\title{
O ensino da Filosofia no Brasil no contexto das políticas educacionais contemporâneas em suas determinações legais e paradigmáticas
}

\section{The teaching of Philosophy in Brazil in the context of contemporary educational policies in its legal and paradigmatic requirements}

\author{
Zita Ana Lago Rodrigues ${ }^{1}$
}

\begin{abstract}
RESUMO
Este texto trata das políticas educacionais contemporâneas no Brasil, da LDBEN 9.394/96, das Diretrizes Curriculares Nacionais (1998), dos PCN-EM (1999) e suas implicações para o ensino da Filosofia no Brasil, abordando aspectos históricos e legais da reinserção desse ensino na escola brasileira de ensino médio, com seus delineamentos legais na LDBEN 9.394/96 e o modo como se tem proposto perspectivas de contraposição às referidas políticas. Questiona os procedimentos relativos a esse processo e levanta algumas sugestões possíveis para ações por parte da Instituição de Ensino Superior, formadora de profissionais para atuar com esses ensinos, e das entidades representativas dos profissionais educadores ligados ao ensino de Filosofia, nessa fase de transições e mudanças paradigmáticas na educação brasileira.
\end{abstract}

Palavras-chave: ensino de Filosofia; políticas educacionais contemporâneas; LDBEN 9.394/96.

${ }^{1}$ Doutora em Educação - Western Illinois University (WIU), USA; Universidade Federal do Rio de Janeiro (UFRJ); docente e palestrante na área educacional e filosófica; docente visitante da Universidade Lusófona de Humanidades e Tecnologias (ULHT), Lisboa-Portugal e pesquisadora da Fundação para a Ciência e a Tecnologia (FCT) Lisboa/Portugal, Brasil. E-mail: zitalago@yahoo.com.br 


\begin{abstract}
This paper discusses the contemporary educational policies in Brazil, in accordance with the LDBEN 9.394/96 law, the National curriculum guidelines (1998), the National Curricular Parameters - PCN-EM (1999) and their implications in the teaching of Philosophy in Brazil, addressing historical and legal aspects of the reintegration of this teaching in Brazilian secondary school with its legal delineation on LDBEN 9.394/96 and the way prospects for opposition have been proposed to the referred policies. It also questions the procedures related to this process and raises some possible suggestions for actions on the part of the higher education institution which holds the professional forming for them to work with that teaching and on the part of representative entities of professional educators connected to the teaching of Philosophy, in this transition phase with paradigmatic changes in Brazilian education.
\end{abstract}

Keywords: teaching Philosophy; contemporary educational policies; LDBEN 9.394/96.

\title{
Aspectos históricos e legais
}

A concepção de Filosofia difundida na educação escolar brasileira historicamente esteve ligada a saberes abstratos e racionalistas, ligados à formação das elites. Suas bases escolásticas desde o Brasil Colônia a desvincularam de características contextualizadas de um ensino voltado à realidade vivencial, afastando-a de possibilidades de reflexão e problematização.

Tal concepção revela as visões idealistas racionais e pragmáticas que até meados do século XX caracterizaram o ensino e os saberes filosóficos no Brasil. Revelam-se aí visões de mundo que permeiam toda a formação recebida pelos professores de Filosofia e que, ao ensinar, a reproduz, com poucas perspectivas de mudanças no contexto educacional em que se inserem, caracterizando-a como algo à margem de estruturações e arquiteturas curriculares críticas e transformadoras. Rever este processo histórico de inclusão/exclusão e procedimentos legais e metodológicos do ensino de Filosofia no Brasil é deveras necessário, para situar melhor a problematização que se pretende desencadear sobre o tema.

No Brasil Colônia, o ensino de Filosofia foi ofertado em reduzido número de Colégios, onde a escolástica era a base do ensino, pela vinculação religiosa dos jesuítas, responsáveis pela educação à época. Até meados do século XX, essa modalidade do ensino da Filosofia esteve presente na escola brasileira, com 
fortes repercussões nos currículos. Com a Reforma Capanema, em 1942, torna-se obrigatório o ensino da Filosofia, de modo especial nas escolas religiosas, que atendiam às elites sociais e econômicas do país.

Com a promulgação da Lei 4.024/61, a Filosofia deixa de ser disciplina obrigatória e passa a disciplina complementar nos currículos escolares. A Lei 5.692, promulgada em 1971, em pleno regime militar, extingue a Filosofia dos currículos, destarte as reações e mobilizações ocorridas no país em prol de sua manutenção/retorno aos currículos escolares. Tais mobilizações estimulam reações em diversos níveis e, por meio do Parecer 7.044/82, do então Conselho Federal de Educação - CFE -, abrem-se possibilidades para o retorno da disciplina de Filosofia aos currículos do Ensino Médio - EM.

A luta e a contestação dos educadores brasileiros e dos setores populares em prol de reformas educacionais, sociais e políticas, desde meados da década de 80, alteram-se e são desestruturadas, por meio da edição da Lei de Diretrizes e Bases da Educação Nacional - LDBEN 9.394/96 -, que desconsidera todo esse processo e esvazia a correlação de forças, a partir do modelo neoliberal que se adota no país, desde o início do governo de Fernando Collor de Mello, consolidando-se e aprimorando-se com os dois períodos de governo de Fernando Henrique Cardoso - FHC - de 1998 a 2002, seguidos da posse de um presidente de linhagem popular e sindicalista, o Presidente Luis Inácio Lula da Silva, governando por oito anos, com uma certa continuidade aos ditames colocados.

"Após uma certa nebulosidade inicial, o governo FHC aos poucos adota e torna claro seu projeto político para a educação nacional", diz Vieira (2000, p. 22). Nesse período governamental (1994-2002), são apresentadas modificações substanciais com relação às políticas educacionais, de acordo com os ditames dos organismos internacionais de financiamento, expressas em documentos oficiais: - a Emenda Constitucional n ${ }^{\circ} 14 / 96$, no capítulo sobre a Educação na Constituição Federal de 1988; - a LDBEN 9.394/96; - a Lei no 9.424/96, lei de criação do Fundo de Manutenção e Desenvolvimento do Ensino Fundamental e da Valorização do Magistério - FUNDEF; - o Plano Nacional de Educação - PNE - Lei $\mathrm{n}^{\circ}$ 10.172/2001, que estipula metas para a educação brasileira no período de 2001 a 2011.

Cada um dos documentos citados registra, em seu conjunto, três linhas de ações explícitas: a) prioridade para o ensino fundamental; b) definição e implementação de reformas institucionais capazes de criar condições de mudanças permanentes nos rumos da educação brasileira, com ênfases na gestão, na qualidade, na eficiência e na avaliação; c) possibilidades de mobilização da sociedade, pela melhoria do ensino público (e privado). (BRASIL, 1995, p. 5). Essas prioridades são demarcadas pelo conceito de que a educação é elemento primordial para o desenvolvimento da nação, dos sujeitos e da cidadania, embora 
não apresente clareza quanto aos mecanismos para promover tal desenvolvimento, desconsiderando abruptamente a relevância dos estudos filosóficos na formação de sujeitos capazes de autodesempenhar as competências básicas para uma cidadania ativa.

\section{A Filosofia no Ensino Médio - trajetórias e perspectivas}

O desenrolar histórico da presença/ausência da Filosofia nos currículos dos cursos de Ensino Médio (ou do anteriormente denominado Segundo Grau) nunca foi linear. Conflitos e resistências têm permeado esse processo. "Até mesmo por se tratar da presença num nível de ensino que passou por sérias crises de identidade, ora voltando-se para a formação profissional, ora à formação geral, a presença da disciplina de Filosofia no Ensino Médio foi problemática". (MARTINS, 2000, p. 100).

O equívoco em que os educadores brasileiros incorreram, de modo especial aqueles vinculados à Filosofia e seu ensino, ao acreditar que, com a LDBEN 9.394/96, o espaço reservado nos currículos do Ensino Médio ao ensino de Filosofia estaria garantido, reforça-se através de uma série de posturas autocráticas e autoritárias do Ministério da Educação - MEC - e do então Presidente FHC, haja vista as ocorrências e decorrências dos trâmites, no Congresso Nacional, do Projeto de Lei - PL 3178/97 -, da autoria de Roque Zimmermann, o qual caracterizou-se como uma grande e trágica polêmica histórica (ZIMMERMANN, 2001).

Pelas determinações da LDBEN 9.394/96, o ensino da Filosofia em nenhum aspecto é proibido, mas, apesar de indicação de sua possibilidade, também não se caracteriza como obrigatório. A determinação de sua inserção dilui-se em considerações e determinações sobre currículo para o Ensino Médio e, no Artigo 36, parágrafo $1^{\circ}$ inciso III, da referida LDBEN, diz-se que:

$\$ 1^{\circ}$ - Os conteúdos, as metodologias e as formas de avaliação serão organizados de tal forma que ao final do ensino médio o educando demonstre:

I - domínio dos princípios científicos e tecnológicos que presidem a produção moderna;

II - conhecimento das formas contemporâneas de linguagem;

III - domínio dos conhecimentos de Filosofia e Sociologia necessários ao exercício da cidadania. (BRASIL, 1996). 
Tais considerações se confirmam com a promulgação das Diretrizes Nacionais para o Ensino Médio - DCNEM - pela Câmara de Educação Básica - CEB - do Conselho Nacional de Educação - CNE/CEB-1998, nas quais se explicita a estruturação do currículo não mais em disciplinas, mas através das chamadas áreas de conhecimento (Artigo 10, itens I, II, III). Nesse sentido, definem-se nas referidas DCNEM três grandes áreas para esse nível de ensino: "- Linguagens e Códigos e suas tecnologias; - Matemática e Ciências da Natureza e suas tecnologias; - Ciências Humanas e suas tecnologias."

$\mathrm{Na}$ Resolução CNE/CEB n ${ }^{0}$ 03/98, de 26 de junho de 1998, que estabelece as DCNEM-1998, considera-se, em seu Artigo $1^{\circ}$, que as mesmas:

[...] se constituem num conjunto de definições doutrinárias sobre princípios, fundamentos e procedimentos a serem observados na organização pedagógica e curricular, de cada unidade escolar integrante dos diversos sistemas de ensino, em atendimento ao que manda a lei, tendo em vista vincular a educação com o mundo do trabalho e a prática social, consolidando a preparação para o exercício da cidadania e propiciando a preparação básica para o trabalho. (BRASIL, 1998b).

No Artigo $3^{\circ}$ das DCNEM estabelecem-se condições para a observância dos valores previstos pela LDBEN 9.394/96, afirmando que sejam "coerentes com princípios estéticos, políticos e éticos [abrangendo] a Estética da Sensibilidade, a Política de Igualdade e a Ética da Identidade". Nos Artigos $4^{\circ}$ e $5^{\circ}$, respectivamente, estabelecem-se normas para os registros das propostas pedagógicas e seus currículos, com determinações específicas para a organização desses currículos no ensino médio.

Os princípios pedagógicos da Identidade, Diversidade e Autonomia, da Interdisciplinaridade e da Contextualização, serão adotados como estruturadores dos currículos do Ensino Médio, sendo apresentados no Artigo $6^{\circ}$ das DCNEM.

No parágrafo $1^{\circ}$ do Artigo 10, da Resolução 03/98, diz-se que: “A base nacional comum dos currículos do Ensino Médio deverá contemplar as três áreas do conhecimento [acima referidas], com tratamento metodológico que evidencie a interdisciplinaridade e a contextualização". (BRASIL, 1998b). No parágrafo $2^{\circ}$ do mesmo Artigo, afirma-se que: "As novas propostas pedagógicas das escolas deverão assegurar tratamento interdisciplinar e contextualizado para: a) Educação Física e Arte, como componentes curriculares obrigatórios; b) conhecimentos de Filosofia e Sociologia necessários ao exercício da cidadania”. (BRASIL, 1998b, grifo nosso). 
Vale aqui ressaltar alguns aspectos contidos no Parecer CNE/CEB n ${ }^{\circ} 15 / 98$, de $1^{\circ}$ de julho de 1998, sob a relatoria da conselheira Guiomar Namo de Mello, cujo Relatório, extenso e minucioso, trata das Diretrizes Curriculares Nacionais para o Ensino Médio -DCNEM -, a serem apresentadas pela Resolução n 3/98 de 26 de junho de 1998, que vem posteriormente dar as Bases aos Parâmetros Curriculares Nacionais para o Ensino Médio - PCNEM, editados em 1999. Os aspectos acentuados nessa proposta de ação pedagógica referem-se aos valores e princípios estéticos, políticos e éticos e à questão da Estética da Sensibilidade, da Política de Identidade e da Ética da Igualdade, propostas no Artigo $3^{\circ}$ da Resolução $n^{\circ} 03 / 98$, ressalta a relatora, e diz que as três consignadas citadas: Sensibilidade, Igualdade e Identidade, já inspiraram a CF/1988 e a LDBEN 9.394/96. Nas considerações sobre a questão em tela, afirma ainda a relatora Mello (BRASIL, 1998c, p. 23), que:

\begin{abstract}
Não é por acaso que essas mesmas competências estão entre as mais valorizadas pelas novas formas de produção pós-industrial que se instalam nas economias contemporâneas. Essa é a esperança e a promessa que o novo humanismo traz para a educação, em especial a média: a possibilidade de integrar a formação para o trabalho num projeto mais ambicioso de desenvolvimento da pessoa humana. [...] portanto, os conhecimentos e as competências cognitivas e sociais que se quer desenvolver nos jovens alunos do Ensino Médio remetem à educação como constituição de identidades comprometidas com a busca da verdade.
\end{abstract}

Nesse sentido, o inciso III do artigo 35 da LDBEN 9.394/96 infere pela necessidade do "[...] aprimoramento do educando como pessoa humana, [...] a formação ética e o desenvolvimento da autonomia intelectual e do pensamento crítico, tarefas que certamente a Filosofia facilitaria no aluno de EM" (BRASIL, 1996). Há clara dicotomia e acentuada dubiedade de colocações entre as duas normatizações legais, a LDBEN 9.394/96 e as DCNEM, 1998 - pois, ao mesmo tempo em que se fala apenas em conhecimentos mínimos de Filosofia no Ensino Médio, atribuiu-se a tais saberes relevante significância, entre elas a de contribuir significativamente "para promover a cidadania."

No entanto, não há que se interpretar tais contradições como simples equívoco, diz Martins (2000), mas sim como parte de um jogo, como peça de um mosaico bem planejado, para que se processe de modo inequívoco, porém não explícito, a lógica que está a mover as reformas educacionais no País, desde o início da década de 1990 - aquela (lógica) do capital internacional 
e dos interesses neoliberais e do mercado que impactam o meio educacional brasileiro e mundial.

Algumas considerações sobre a LDBEN 9.394/96 talvez contribuam para uma melhor análise da questão, que em seu artigo 26 diz: "Os currículos do ensino fundamental e médio devem ter uma base nacional comum, a ser complementada, em cada sistema de ensino e estabelecimento escolar, por uma parte diversificada exigida pelas características regionais e locais da sociedade, da cultura, da economia e da clientela" (BRASIL, 1996).

Nos cinco parágrafos que compõem e complementam este artigo são apresentadas algumas referências a essa ou aquela disciplina, no entanto, sem referências explícitas à inclusão da Filosofia como disciplina obrigatória no currículo do Ensino Médio - EM, conforme seu Artigo 27, que reza:

Os conteúdos curriculares da educação básica observarão, ainda, as seguintes diretrizes:

I - difusão de valores fundamentais ao interesse social, aos direitos e deveres dos cidadãos, de respeito ao bem comum e à ordem democrática; II - consideração das condições de escolaridade dos alunos em cada estabelecimento;

III - orientação para o trabalho;

IV - promoção do desporto educacional e o apoio às práticas desportivas não formais. (BRASIL, 1996).

Por sua vez, na sequência das normatizações da LDBEN 9.394/96, no Artigo 35 estabelece-se que:

O Ensino Médio, etapa final da educação básica, com duração mínima de três anos, terá como finalidade:

I - a consolidação e o aprofundamento dos conhecimentos adquiridos no ensino fundamental, possibilitando o prosseguimento de estudos; II - a preparação básica para o trabalho e a cidadania do educando, para continuar aprendendo, de modo a ser capaz de se adaptar com flexibilidade a novas condições de ocupação ou aperfeiçoamento posteriores;

III - o aprimoramento do educando como pessoa humana, incluindo a formação ética e o desenvolvimento da autonomia intelectual e do pensamento crítico;

IV-a compreensão dos fundamentos científicos dos processos produtivos, relacionando a teoria com a prática, no ensino de cada disciplina. (BRASIL, 1996). 
Conforme já se expôs anteriormente, no parágrafo $1^{\circ}$, inciso III do Artigo 36, é onde se faz explícita referência "aos conhecimentos de Filosofia (e Sociologia) necessários ao exercício da cidadania”, os quais deverão ser ofertados em forma de conteúdos, cujas metodologias de ensino e formas de avaliação contemplem o exposto nos artigos anteriores $-27,35$ e o próprio 36 , onde se faz referência aos saberes necessários ao aluno do ensino médio.

Assim, é possível perceber que a Filosofia é contemplada referencialmente apenas como conhecimentos a serem dominados e demonstrados ao final do EM. De algum modo, indica-se a necessidade de que a Filosofia faça parte dos conteúdos a serem tratados no EM. Difere tal indicação do modo como, nos cinco parágrafos do artigo 26 da LDBEN 9.394/96, se expõe a obrigatoriedade de presença na estrutura curricular dos cursos de ensino médio da língua portuguesa, da matemática, das ciências naturais, das ciências que tratam da realidade social e política, das artes, da educação física, da história e da língua estrangeira.

Se a lei educacional maior do país não aponta objetiva e diretamente a obrigatoriedade da presença da Filosofia no currículo, permanecendo sua indicação apenas como "conhecimentos a serem dominados pelo aluno ao final do ensino médio", sua oferta será, portanto, decorrente da vontade expressa dos gestores da escola, a qual poderá ou não ofertá-la no percentual de $25 \%$ das disciplinas complementares ao currículo pleno.

\section{A Filosofia como disciplina - o projeto de Lei 3.178/97 e seus trâmites}

Todo o movimento de contestação e resistência ao modo como se tratou a questão do ensino da Filosofia ao longo das duas últimas décadas, em especial na LDBEN 9.394/96, resulta no entendimento da necessidade de alterar o proposto na referida lei maior da educação brasileira.

Na sequência dos debates e da justificação de sua presença, definindo-se sua exata contribuição, ou seja, ser capaz de dizer ao que veio, conforme diz Severino (1980), e do seu real papel no contexto escolar contemporâneo, de acordo com Lago Rodrigues (2001), é apresentado na Câmara dos Deputados, em 1997, o Projeto de Lei - PL 3.178/97, de autoria de Roque Zimmermann, tornando a Filosofia e a Sociologia disciplinas obrigatórias nos currículos do Ensino Médio.

O referido projeto propõe modificações na LDBEN 9.394/96 com relação ao ensino da Filosofia no Ensino Médio e, num primeiro momento de apreciação nas Comissões Temáticas, obteve parecer favorável na Comissão de Educação, 
Cultura e Desporto - CECD -, encarregada da análise do mérito e da avaliação e apreciação inicial do Projeto de Lei - PL. A Comissão de Constituição e Justiça - CCJ - da Câmara Federal, encarregada da apreciação da juridicidade, constitucionalidade e técnica legislativa, também aprova o PL 3.178/97. O poder terminativo das referidas Comissões dispensou seu trâmite pelo Plenário da Câmara dos Deputados, sendo que, imediatamente após as apreciações das duas Comissões, o PL foi encaminhado ao Senado Federal, em 13 de abril de 2000.

Os trâmites pelo Senado Federal seguiram as ritualísticas legislativas de praxe e, ressaltando-se o mesmo poder terminativo das Comissões encarregadas da apreciação do PL 3.178/97, o referido Poder Legislativo faz com que ambas as comissões, de Educação e de Justiça, por intermédio dos Senadores José Fogaça (Justiça) e Álvaro Dias (Educação), apresentem pareceres favoráveis à aprovação da obrigatoriedade da inclusão das disciplinas de Filosofia e Sociologia nos currículos do Ensino Médio.

Em documento apresentado no III Encontro dos Cursos de Filosofia do Sul do Brasil e I Simpósio Sul-Brasileiro sobre o Ensino de Filosofia, realizado na Universidade de Passo Fundo - UFP, em abril de 2001, o Deputado Roque Zimmermann apresenta os quatro argumentos centrais que fundamentaram sua intenção ao apresentar o PL 3.178/97, sendo eles:

1. A retirada da Filosofia e da Sociologia dos currículos da escola média pelos governos da ditadura militar, sendo substituídas por disciplinas como Organização Social e Política Brasileira - OSPB - e Estudo de Problemas Brasileiros - EPB. A lenta reinclusão, em algumas escolas, da disciplina de Filosofia e, por último, as considerações da LDBEN 9.394/96, entendendo a necessidade de serem tratadas apenas como "conteúdos mínimos";

2. As amplas reformas do ensino médio, promovidas pelo MEC, separando-o da educação profissional, rebaixando a qualidade dos conteúdos, através da áreas de concentração, conforme a Resolução ${ }^{\circ}$ 03/98 do CNE, tratando das Diretrizes Curriculares Nacionais para o Ensino Médio;

3. O reconhecimento do status de disciplina à Filosofia e à Sociologia é o reconhecimento de seu estatuto epistemológico, próprio a estas duas ciências - Filosofia e Sociologia, importantes e fundamentais para o desenvolvimento humano. Constituí-las como disciplinas na arquitetura curricular do ensino médio nas escolas brasileiras significa muito mais do que reforçar compartimentações, mas reconhecer seu status epistemológico e sua relevância histórica para a formação da capacidade crítico-reflexiva e da ampliação da capacidade da construção da cidadania do alunado que acessa esse nível de escolarização formal; 
4. Apesar da redução da busca pelas licenciaturas, muitos jovens têm buscado, nos últimos anos, cursos de graduação e pós-graduação em Filosofia e Sociologia, sendo muitas as Universidades e Instituições de Ensino Superior - IES - que os ofertam com qualidade. Tais profissionais formados e habilitados nesses cursos poderiam atuar na educação, o que abriria possibilidades de trabalho para milhares de jovens por todo o país, além de melhorar significativamente o nível de conhecimentos e de formação dos alunos do ensino médio. (ZIMMERMANN, 2001).

Considera ainda o parlamentar paranaense que, mais do que simplesmente introduzir mais uma ou duas disciplinas no currículo do Ensino Médio, a intenção é levantar o debate sobre a questão da qualidade desse ensino, cujo cunho técnico reduz as possibilidades de um ensino humanista. Afirma Zimmermann (2001, p. 7) que "no caso específico da Filosofia, que se constitui como crítica profunda tanto das compartimentações positivísticas quanto das diluições superficiais, é muito difícil visualizar condições para que seja trabalhada a modalidade como está atualmente"; e diz não discordar da apresentação dos currículos do Ensino Médio com os princípios estruturadores da Diversidade e Autonomia, da Interdisciplinaridade e da Contextualização, fundamentais para que se supere a visão fragmentária do currículo escolar, advogando o efetivo reconhecimento da importância da Filosofia e da Sociologia como disciplinas obrigatórias no currículo do Ensino Médio. Ressalta o parlamentar que os argumentos que se opõem à criação do espaço disciplinar obrigatório à Filosofia não são de ordem pedagógica, epistemológica ou de política educacional. Tais argumentos são de natureza estritamente burocrática e giram em torno do fato de que o resultado imediato será a necessidade de abrir concurso, contratar professores para a escola pública, o que irá gerar despesas, caracterizando-se assim como uma questão econômica. Tal argumento sustentou o veto presidencial à obrigatoriedade do ensino de Filosofia e Sociologia, após a aprovação definitiva do PL 3.178/97 pelo Senado Federal, em setembro de 2001.

A aprovação do referido projeto ocorreu de modo efetivo pelos parlamentares, após algumas objeções em Plenário, por parte de representantes do governo no Senado Federal. Porém, após parecer desfavorável do Ministro da Educação, o Presidente Fernando Henrique Cardoso veta definitivamente o Projeto de Lei e sepulta, com isto, a expectativa de milhares de educadores ligados à Filosofia e seu ensino. Então, questiona-se: como agir? 


\section{Caminhos (im)possíveis para a ação - à guisa de conclusão}

Se entendermos com Kosik (1989, p. 13) que "A Filosofia é uma atividade humana indispensável."; com Favaretto (1993, p. 97) que "Esta crise da Filosofia, independentemente da perda de seu assunto [espaço] instituído, provoca a sua valorização e o desenvolvimento de um novo estilo de filosofar", e que há sempre uma intencionalidade em todo e qualquer ensino: a de produzir aprendizagem, tais considerações ficarão melhor compreendidas mediante as colocações de Etiènne Tassin (1986) ao considerar que, para examinar o valor formador da Filosofia, dever-se-á valorizar o fato de que esta desenvolve capacidade de leitura, de análise, de crítica, de abstração; induz ao sentido do questionamento e da problematização sobre as realidades em estudo e desenvolve técnicas de argumentação e elaboração de raciocínio; abre para interrogações conceituais e para reflexões racionais; instaura certa distância crítica e convida ao retorno reflexivo sobre si e sobre as condições de possibilidade do pensamento e que é tarefa elucidativa de nossa relação com o mundo.

Muitas argumentações poderão ser acrescentadas sem perder o foco e a captação de sua especificidade no contexto arquitetônico curricular da escola de ensino médio. É significativo ponderar com Dreyfus e Khodoss (1986, apud TASSIN, 1986, p. 1008-1009), que:

O ensino filosófico deverá mostrar aos alunos os procedimentos das enunciações verdadeiras e isso diz respeito à disciplina da razão. É, portanto, por natureza, racional, dirige-se à razão, educa-a, procede por raciocínios, introduz na racionalidade [...]. Possibilita a síntese conceitual [da realidade] que, para determinada época, é a sua verdade.

Sendo assim, na tentativa de apresentar sínteses conceituais superadoras, cabe-nos, enquanto voltados à problemática do ensino da Filosofia e sua trajetória polêmica e trágica, conforme a afirmativa de Zimmermann (2001), pensar alguns caminhos (im)possíveis para a ação e para a problematização do instituído.

Considera-se sejam caminhos difíceis, mas questionadores, utópicos, talvez, porém, intransferíveis, como tarefa que cabe no seu traçado, na sua busca, na sua concretização, a todos e a cada um dos professores de Filosofia no Ensino Médio e na Educação Superior, ao proceder ações contestatórias e elucidativas sobre a problemática, analisando os modos paradoxais com que se define a importância dos saberes filosóficos quando, concomitantemente, considera-se a dispensabilidade dos mesmos como obrigatórios no currículo, sendo somente 
"recomendáveis como conteúdos mínimos", nas proposições legais das atuais políticas educacionais no país.

Então, questiona-se: - Que atitude ou atitudes tomar, então? - Como seria mais recomendável agir? - De que modo proceder frente aos ditames legais?

Recolher-se aos catastrofismos?, questionaria Emmanuel Mounier (1979). Assumir subserviência?, indagaria Dermeval Saviani (1986). Afrontar, buscar, utopizar, proporia o próprio E. Mounier (1979) e visualizar possibilidades e alternativas contextualizatórias, dizemos nós; sendo possível que em assembleias e espaços de discussão e crítica, a exemplo dos Simpósios de Filosofia do Fórum Sul, em grupos reflexivos desse porte, que sejam abertas prospectivas dialogais, teleologias e alternativas instituintes e com isto passem elas a serem instituídas, de fato e de direito, concretizando as protopias - colocando-se a caminho da ação - superando assim as meras utopias e os simples desejos de mudança.

São questões que se apresentam nesses momentos de questionamento e de modificações sobre o currículo escolar, sempre pouco discutido nas instâncias microestruturais que os executam, mas sugere-se que as IES e as Universidades proponham formações sólidas e qualitativas de formação para os cursos superiores de Filosofia; que se debata a questão da Filosofia e o de seu ensino nos currículos do Ensino Médio e na Educação Superior, onde gradativamente tem-se percebido o enxugamento de seus espaços nos currículos dos cursos superiores.

E mais ainda, que se instalem assembleias, fóruns, seminários, simpósios, encontros e outros eventos do gênero, com vistas a manter aceso o debate permanente sobre a importância do pensar filosófico, da Filosofia e de seu retorno e permanência nos currículos escolares, em qualquer dos níveis da educação formal. Propomos, portanto, que se propiciem reflexões sobre:

- o espaço dado ao ensino da Filosofia pela LDBEN 9.394/96 e o verdadeiro papel crítico-político-ético-reflexivo desse ensino;

- o suposto humanismo presente no teor das normatizações legais: LDBEN 9.394/96, DCN e PCN para o Ensino Médio;

- a dicotomia presente entre as competências e habilidades propostas para serem desenvolvidas com o alunado do ensino médio e o papel efetivo do filosofar; - a pretensa flexibilidade das atuais políticas educacionais, traçadas e normatizadas pela LDBEN 9.394/96, pelos PCN-EM e pelas DCN de Qualidade para os Cursos Superiores, com pouca possibilidade e abertura para que se elaborem legislações complementares, restritivas, cerceadoras e limitantes de um verdadeiro educar, como consequência da própria falta de objetividade e clareza dessas normatizações legais;

- a lógica mercadológica dos PCN e das DCN para o EM, propondo questionáveis modelos de sociedade e de cidadania em sua desvinculação com a realidade atual e contextual da sociedade brasileira; 
- o tipo de organização curricular proposto para o EM e o esvaziamento de aspectos formadores para aqueles que frequentam esse nível de ensino;

- a proposta de cidadania autônoma e emancipatória e o paradoxo que se estabelece através da lógica do mercado que determina "essa tal cidadania", da produção e do consumo;

- o esvaziamento dos cursos superiores de Filosofia (entre outras licenciaturas), pelo cerceamento de espaços para a ação dos profissionais neles habilitados, privilegiando-se sempre aqueles cursos cujo status socioeconômico, de acordo com a lógica mercadológica e pragmática atual, sejam mais relevantes para o desenvolvimento do país e para a ascensão profissional de seus egressos.

São questões como estas que deverão nortear os caminhos (im)possíveis para a ação contestatória e reivindicatória, aprofundando-se discussões sobre a natureza, o papel e o espaço da Filosofia, definindo seus eixos norteadores e espaços adequados a cada nível de ensino, seja ele fundamental, médio ou superior, para "não cair em confusões que poderiam ser evitadas", diz Rocha (apud GALLO; KOHAN, 2000, p. 157).

Portanto, para que se caracterize, conforme propõe Chauí (1994), a verdadeira "atitude filosófica", tão carente e tão necessária em tempos de perdas de referenciais de bases sólidas, em tempos de topóis definitivos e securizantes, que levam a exigências urgentes de mudanças paradigmáticas, necessita-se da ampliação das possibilidades e das alternativas no caminho da realização das necessárias e possíveis protopias construtivas no fazer educação e na formação daqueles que a fazem em seu cotidiano profissional - os professores e docentes!

\section{REFERÊNCIAS}

BRASIL. Relatório de Atividades do ano de 1995. Brasília, DF, 1995.

. MEC. Lei de Diretrizes e Bases da Educação Nacional - LDB 9.394/96. Brasília, DF: MEC, 1996.

. MEC/CNE. Diretrizes Curriculares Nacionais para o Ensino Médio. DCNEM

- CEB/CNE. Brasília, DF, 1998a.

. MEC/CNE. Resolução CEB n $n^{o .}$ 3. Brasília, DF, 26 de junho, 1998b.

. MEC/CNE. Parecer CEB n $n^{\circ}$ 15/98. Brasília, DF, 1 julho, 1998c.

. MEC/CNE. Parâmetros Curriculares Nacionais para o Ensino Médio. PCN-

-EM. Brasília, DF, 1999. 
CARMINATI, C. J. Pressupostos teóricos e epistemológicos do ensino de Filosofia no $2^{\circ}$ grau. Revista Alcance, Itajaí (SC), ano VI, n. 2, p. 52-57, out. 1999.

CHAUÍ, M. Convite à Filosofia. São Paulo: Brasiliense, 1994.

FAVARETTO, C. F. Sobre o ensino de Filosofia. Revista da Faculdade de Educação, São Paulo, v. 19, n. 1, p. 97-102, jan./jun. 1993.

GALlinA, S. F. da S. A disciplina de Filosofia e o Ensino Médio. In: GALLO, S.; KOHAN, W. O. (Orgs.). Filosofia no Ensino Médio. Petrópolis: Vozes, 2000.

GALLO, S.; KOHAN, W. O. (Orgs.). Filosofia no Ensino Médio. Petrópolis: Vozes, 2000.

HORN, G. B. A presença da Filosofia no currículo do Ensino Médio Brasileiro: uma perspectiva histórica. In: GALLO, S.; KOHAN, W. O. (Orgs.). Filosofia no Ensino Médio. Petrópolis: Vozes, 2000.

LAGO RODRIGUES, Z. A. O papel da Filosofia no mundo contemporâneo. In:

Ciência, Filosofia e conhecimento: Leituras paradigmáticas. Palmas, PR: Kaigangue, 2001.

KOSIK, Karel. Dialética do concreto. Rio de Janeiro: Paz e Terra, 1989.

MARTINS, M. F. Uma nova Filosofia para o Ensino Médio. In: GALLO, S.; KOHAN, W. O. (Orgs.). Filosofia no Ensino Médio. Petrópolis: Vozes, 2000.

MOUNIER, E. O personalismo. Lisboa: Edições 70, 1979.

PEREIRA, F. D. Ensino de Filosofia e problematização da concepção pragmática da realidade. Revista UNIFEO, dezembro 1998.

ROCHA, R. Filosofia como educação de adultos. In: GALLO, S.; KOHAN, W. O. (Orgs.). Filosofia no Ensino Médio. Petrópolis: Vozes, 2000.

SAVIANI, D. Educação do senso comum à consciência filosófica. São Paulo: Cortez, 1986.

SEVERINO, A. J. O papel da Filosofia no Brasil: compromissos e desafios atuais. Revista Reflexão, Campinas: Cortez, n. 17, p. 5-11, maio/ago. 1980.

TASSIN, E. La valeur formatrice de la Philosophie. In: DERRIDA, J. et al. La greve des philosophes. Paris: Osiris, 1986.

VIEIRA, S. L. Politica educacional em tempos de transição. Brasília, DF: Plano, 2000.

ZIMMERMANN, R. A nova LDB e o ensino de Filosofia: considerações sobre a legislação e o PL 3178/97. Mimeo. 2001.

Texto recebido em 20 de fevereiro de 2012.

Texto aprovado em 15 de junho de 2012. 